\title{
Judgments of deceptive communications: A multidimensional analysis
}

\author{
WILLIAM R. POPE \\ Mary Washington College, Fredericksburg, Virginia \\ and \\ DONELSON R. FORSYTH \\ Virginia Commonwealth University, Richmond, Virginia
}

Four dimensions underlying individuals' perceptions of various types of lies were identified through multidimensional scaling: (1) intentions of liar (benign vs. malign), (2) purposes of lie (instrumental vs. protective), (3) responsibility of liar for lie (freely done vs. constrained by situation), and (4) consequences of lie (severely negative vs. mild). Judgments of morality were most closely related to intentions and consequences, replicating results of past research that indicate that outcome quality plays a major role in determining moral judgments, but that intentionality also plays a role.

In this research, we sought to establish a basis for systematic studies of lying and liars by exploring evaluations of various types of deceptions. Although several studies of reactions to lies have been carried out in recent years (e.g., Maier \& Lavrakas, 1976), these investigations have been limited in scope because of the tremendous diversity of possible lies. Furthermore, attempts have been made to create classifications of lies (Bok, 1978), but for the most part these typologies have been philosophically grounded rather than empirically based. Given these limitations, we had, in the current investigation, two interrelated objectives. First, through the application of multidimensional scaling (MDS), we identified the perceptual dimensions underlying various types of lies. Second, we examined the relationships between these dimensions and moral evaluations to determine how subjects evaluated lies based on their underlying perceptual dimensions.

Drawing on attributional analyses of moral evaluation (e.g., Lane \& Anderson, 1976; Nesdale, Rule, \& McAra, 1975; Shaw \& Sulzer, 1964), we identified two hypothesized dimensions: intentions of the liar and type of consequences created. Although additional dimensions may also underlie perceptions of lies (e.g., foreseeability, justification), we predicted that individuals would distinguish between lies told with positive rather than negative intentions, and lies that led to good rather than bad consequences. Furthermore, these two dimensions should be important mediators of moral judgments of lies, for lies told with a malicious intent aimed at negative consequences should be most strongly condemned, whereas lies leading to positive consequences and told by a wellintentioned individual should be most favorably evaluated.

Requests for reprints should be sent to D. R. Forsyth, Department of Psychology, Virginia Commonwealth University, $810 \mathrm{~W}$. Franklin Street, Box 2018, Richmond, VA 23284.

\section{METHOD}

Before we asked subjects to rate lies, we collected a representative sampling of deceptions by asking a large group of introductory psychology students $(N=153)$ to write short descriptions of situations in which one person lies to another. From this large bank of lies, 15 deceptions were selected as representative of the larger group and were rewritten to increase comparability in length and language. Some examples are:

Susan tells her professor she cannot take the exam on time because she has a doctor's appointment. Susan does not have an appointment, but does not feel prepared and wants extra time to study.

Jeff lied to his parents and said he was going to a basketball game at school. Instead he went to a party. On the way home he wrecked his parents' car and was seriously hurt.

Nancy was up for a big promotion. Her boss, Dave, disliked her for personal reasons. He lied and kept her from getting the job.

Seventeen females, recruited from the introductory psychology research-participant pool, read the 15 descriptions to themselves. Then, in a randomized series of 105 paired comparisons, subjects compared each situation to every other situation. Each pair was presented on a separate page of a questionnaire booklet in the following format (the last two examples shown above are used for this comparison):

$$
\text { Party - - - - - - - Promotion }
$$

$\begin{array}{llllllllllll}\text { Very Dissimilar } & 9 & 8 & 7 & 6 & 5 & 4 & 3 & 2 & 1 & \text { Very Similar }\end{array}$

Subjects were told to circle the number that accurately reflected the similarity or dissimilarity of the lies told in the two situations.

After completing the paired-comparisons task, subjects rated each lie on six 9-point Likert-type scales with labeled end points. These items, which were used to interpret the dimensions extracted via MDS, included measures of outcome quality, amount of harm, morality, foreseeability, intentionality of the lie, and situational constraint.

\section{RESULTS}

An individual-differences model of MDS (alternating least squares scaling, ALSCAL; Takane, Young, \& DeLeeuw, 1977) was used to extract the dimensions underlying subjects' similarity judgments. Four dimensions provided the best overall fit with the data, with a stress 
Table 1

Correlations Between Derived Perceptual Dimensions and Supplemental Rating Items

\begin{tabular}{lcccccc}
\hline & \multicolumn{5}{c}{ Item } \\
\cline { 2 - 6 } Dimension & $\begin{array}{c}\text { Outcome } \\
\text { Quality }\end{array}$ & $\begin{array}{c}\text { Amount } \\
\text { of Harm }\end{array}$ & Foreseeability & $\begin{array}{c}\text { Morality } \\
\text { of Lie }\end{array}$ & $\begin{array}{c}\text { Intentionality } \\
\text { of Lie }\end{array}$ & $\begin{array}{c}\text { Situational } \\
\text { Constraint }\end{array}$ \\
\hline $\begin{array}{l}\text { Intentions of Liar: } \\
\text { Benign vs. Malign }\end{array}$ & -.43 & -.41 & -.11 & $-.56^{*}$ & -.24 & .33 \\
$\begin{array}{l}\text { Purpose of Lie: } \\
\text { Instrumental vs. }\end{array}$ & -.20 & -.05 & -.33 & -.12 & .37 & .00 \\
$\begin{array}{l}\text { Protective } \\
\begin{array}{l}\text { Responsibility for Lie: } \\
\text { Freely Done } \\
\text { vs. Coerced }\end{array}\end{array}$ & .42 & .34 & -.20 & .41 & .20 & $-.69 *$ \\
$\begin{array}{l}\text { Consequences of Lie: } \\
\text { Severely Negative } \\
\text { vs. Mild }\end{array}$ & $.67 *$ & $.71 *$ & -.18 & $.53 *$ & .30 & .17 \\
\hline
\end{tabular}

Note $-n=15$ (the number of stimuli being evaluated). Higher scores for the item indicate more negative outcome, more severe harm, more foreseeability, and greater immorality, intentionality, and situational constraint. Higher dimension weights indicate that lies are more benign than malign, more instrumental than protective, more freely done than coerced, and more negative than mild. ${ }^{*} p<.05$.

value of .12 (as stress approaches 0.0 , perfect "fit" is obtained) and an overall $R^{2}$ (percentage of variance accounted for by the solution) of .80 . These stress and $R^{2}$ values were a significant improvement over those for the three-dimensional case (stress $=.17$ and $R^{2}=.74$ ); additional dimensions beyond four failed to yield any substantial improvement.

Table 1 contains the dimensions obtained through MDS as well as the correlations between the stimulus weights on each dimension and the ratings of the stimuli on the six supplemental items. Inspection of this table, in combination with the analysis of the weights of each lie on each dimension, reveals the following four dimensions: Intentions of liar-benign (complimenting another or keeping a child from playing in the street) versus malign (taking advantage of another person or avoiding punishment for wrongdoing). Purpose of lie-instrumental (to achieve a certain goal, such as ruining another's career or avoiding a date) versus protective (to avoid an unpleasant outcome). Responsibility for the lie-freely done (not constrained by pressures in the situation, as when someone lies to another about parking regulations) versus coerced (constrained by situational pressures, as when terminal cancer victims are told that they will recover soon). Consequences of the lie-severely negative (physical damage or personal injury) versus mild (no harm done; the recipient of the lie feels good).

As predicted, two of the four dimensions were found to be closely associated with judgments of the morality of the lie: intentions of the liar and consequences of the lie. Taking these two dimensions into account, we see that a lie told with malevolent intentions that yields highly negative outcomes (e.g., a husband lying to his wife about working late at the office so that he can rendezvous with another woman) is judged to be immoral (mean $=8.06$ on a 9-point scale), whereas a lie told for benevolent reasons that yields a mildly positive outcome (e.g., a mother lying to her child so that the child avoids playing in a dangerous street) is judged more positively (mean $=4.06$ ).

\section{DISCUSSION}

The findings of the current study suggest that four dimensions underlie perceptions of lies, and that moral judgments depend, in part, upon the classification of lies along these dimensions. Analysis revealed that judgments covaried most closely with the liar's intentions and the judged quality of the consequences, but perceptions of responsibility also played a role. Interestingly, individuals also distinguished between lies told to achieve some specific, identifiable goal and those told to extricate oneself from a threatening situation, but this dimension was not significantly correlated with moral judgments.

Of course, the current investigation is limited, because the ratings were supplied by women rather than both women and men and because only 15 stimulus lies were used. The results, however, are quite consistent with previous theory and research, and, if generalized, indicate that individuals do indeed draw distinctions between various types of lies. Although many kinds of lies have been identified in previous philosophical and psychological work, the current project identified eight basic "types" of lies: white (benign) lies, black (malicious) lies, instrumental lies, defensive lies, chosen lies, justified lies, negativeoutcome lies (or, more simply, "bad"' lies), and positive-outcome lies ("good" lies). The questions of whether such a typology of lies is accurate and whether such a framework is utilitarian remain to be explored in future research.

\section{REFERENCES}

BoK, S. (1978). Lying: Moral choice in public and private life. New York: Pantheon.

LANE, J., \& ANDERSON, N. H. (1976). Integration of intention and outcome in moral judgment. Memory \& Cognition, 4, 1-5.

MAIER, R. A., \& LAVRAKAS, P. J. (1976). Lying behavior and the evaluation of lies. Perceptual \& Motor Skills, 42, 575-581.

Nesdale, A. R., Rule, B. G., \& McArA, M. J. (1975). Moral judgments of aggression: Personal and situational determinants. European Journal of Social Psychology, 5, 339-349.

Shaw, M. E., \& Sulzer, J. L. (1964). An empirical test of Heider's levels in the attribution of responsibility. Journal of Abnormal \& Social Psychology, 69, 39-46.

Takane, Y., Young, F. W., \& Deleeuw, J. (1977). Nonmetric individual differences, multidimensional scaling: An alternating least squares method with optimal scaling features. Psychometrika, 42, 7-67.

(Manuscript received for publication July 24, 1986.) 